\title{
Climate adaptation: lessons and insights for governance, budgeting, and accountability
}

\author{
Roz Price \\ Institute of Development Studies \\ 20 December 2021
}

\section{Question}

What current knowledge, best practices, evidence and experiences is available on public sector reform and accountability programmes that support improved adaptation and resilience and the management of climate resources? Specifically:

- $\quad$ Support to policy, planning and budgeting processes as a means to implement climate objectives and improve accountability for climate finance (with a focus on adaptation/ resilience but recognising the public planning/ budgeting processes also need to cover mitigation).

- Use of politically smart/ coalition-based approaches to tackle obstacles to climate governance reform/ more focus on climate issues and improve demand for accountability in government delivery. This will likely include citizen- driven initiatives.

\section{Contents}

1. Summary

2. Governance and climate objectives

3. Climate finance and green public financial management (PFM)

4. Lessons learned and guiding principles for green PFM reform

5. Lessons and insights on transparency and accountability in green PFM

6. References

The K4D helpdesk service provides brief summaries of current research, evidence, and lessons learned. Helpdesk reports are not rigorous or systematic reviews; they are intended to provide an introduction to the most important evidence related to a research question. They draw on a rapid deskbased review of published literature and consultation with subject specialists. 


\section{Summary}

Given the breadth of issues in relation to the governance of climate change and public sector reform, this rapid review is limited to focusing on the two sub-questions. This rapid review only touches briefly on climate governance issues and different approaches to tackle obstacles to climate governance reform. More detail is given on reform programmes that support the management of climate finance and adaptation budgeting and also accountability mechanisms. Some issues that are important but peripheral are touched on but not explored in detail (such as climate change mainstreaming), where possible further reading is highlighted.

This rapid review draws on literature from academic, policy and non-governmental organisation sources. There is a huge literature on climate governance issues in general, but less is known about effective support and the political-economy of adaptation. A large literature base and case studies on climate finance accountability and budgeting in governments is nascent and growing. A number of previous K4D helpdesks provide useful insights into different aspects of climate governance and may also be useful to consider. Two previous helpdesks look at the political economy of climate change issues, one looking specifically at political economy analysis approaches (Price, 2021b) and the other at the political will of African governments to address climate change (Lucas, 2019). A previous K4D helpdesk on Mainstreaming climate and environmental considerations into existing development programmes (Price, 2019) provides some insights into the gaps, challenges and practices of mainstreaming climate considerations into diverse areas such as national policy-making, sectoral planning and project development. Also highlighting how there is no "blueprint" approach for mainstreaming climate considerations and no agreed upon definition or accepted consensus of what climate change mainstreaming is to achieve (i.e. when it is effective and how this could be measured).

Section 2 of this report briefly discusses governance of climate change issues, with a focus on the complexity and cross-cutting nature of climate change compared to the often static organisational landscape of government structured along sectoral lines. It also touches on the need for multi-scalar climate governance, how political institutions (both formal and informal) can support governance for climate resilience, and the importance of political-economy analysis. Accountability mechanisms in climate change framework legislation are also briefly mentioned. Section 3 explores green public financial management (PFM), touching briefly on the major entry-points for adaptation in the budget cycle, the importance of civil society engagement in accountability of climate finance (and some lessons learned in the design of these programmes), and the barriers and challenges to adaptation budgeting and accountability mechanisms. Section 4 then brings together a number of principles and lessons learned on green PFM highlighted in the guidance notes. Many of the notes reflect the same principles and also similar stages of the PFM cycle for the integration process and methodology. Transparency and accountability lessons are then highlighted in Section 5. The notes provide much more detailed information then is summarised here. Most of the experiences and lessons learned on green PFM are drawn from Asian countries, with some experiences from OECD countries. Two recent reports from the Inclusive Budgeting and Financing for Climate Change in Africa Programme (IBFCCA) ${ }^{1}$ touch on

\footnotetext{
${ }^{1}$ The Inclusive Budgeting and Financing for Climate Change in Africa Programme (IBFCCA) aims to strengthen links between national climate change policy and domestic public finances, with the aim of promoting climate
} 
a number of the issues highlighted from the other guidance notes in relation to African country experiences, although they note that experiences and evidence is limited (CABRI, 2021a, b, c).

Key findings:

- Engaging with the governance context and the political economy of climate governance and financing is crucial to climate objectives being realised.

- More attention is needed on whether and how governments are prioritising adaptation and resilience in their own operations, including whether policies and plans and their respective annual budgets and investment frameworks integrate such considerations (Krishnan, 2020).

- Countries in Africa further along in the green PFM agenda give accounts of reform approaches that are gradual, iterative and context-specific, building on existing PFM systems and their functionality. They also express the value in anchoring reforms in international commitments such as Nationally Determined Contributions and the UNFCCC Gender Action Plan as well as regional climate and sustainable development agendas (CABRI, 2021b, p. 5).

- A well-functioning "accountability ecosystem" is needed in which state (legislatures and SAls) and non-state (civil society organisations (CSOs), media, academia, and citizens) accountability actors engage with one another and the executive to improve climate change-related budget policies, monitor execution, and contribute to oversight (UNDP \& IBP, 2018). However, in Africa especially, evidence of this is lacking (CABRI, 2021c).

- However, climate change finance accountability systems and ecosystems in countries are at best emerging. Signs of good progress are nascent within civil society work on climate change financing - for example in Nepal, the Philippines, and Bangladesh (UNDP \& IBP, 2018; UNDP, 2021). These accountability fault lines are for the most part not specific to climate change, but instead a function of the public finance management and accountability ecosystem overall. Strengthening these systems may take several years, especially when core systems are weak.

- Although case studies from Nepal, the Philippines and Bangladesh are commonly cited in the literature and are seen as some of the most advanced developing country examples of green PFM, none of the countries have had significant examples of collaboration and engagement between actors (particularly parliaments and CSOs). Capacity building of CSOs and media and building collaborative approaches between actors are seen as key areas for intervention and support (UNDP \& IBP, 2018).

- Lessons and guiding principles for green PFM reform include: use the existing budget cycle and legal frameworks; ensure that the basic elements of a functional PFM system are in place; strong leadership of the Ministry of Finance (MoF) and clear linkages with the overall PFM reform agenda are needed; smart sequencing of reforms; real political ownership and clearly defined roles and responsibilities; and good communication to stakeholders (Allan et al., 2019; Gonguet et al., 2021; UNDP \& IBP, 2018; UNDP, 2021; World Bank, 2014, 2021). Seeing climate budget tracking as a first step not an end in itself is also important (Allan et al., 2019; World Bank, 2021).

resilience (CABRI, 2021b). See https://www.cabri-sbo.org/en/events/the-integration-of-climate-change-intobudgeting-and-finance 
- Lessons and insights for transparency and accountability mechanisms in green PFM include: importance of public participation and inclusion of civil society organisations (CSOs) for accountability; need for comprehensive and uniform reporting practices and common definitions of climate practices; public availability of data for transparency; inclusion of both negative and positive climate impacts of policies in budget documentation; engagement with sub-national governments and state-owned enterprises; importance of expertise and capacity building support to CSOs and political institutions; continuous political-economy analysis and contextual assessment to inform programming and CSO engagement. (Allan et al., 2019; CABRI, 2021b; Gonguet et al., 2021; Krishnan, 2020; UNDP \& IBP, 2018; UNDP, 2021; World Bank, 2021).

\section{Governance and climate objectives}

\section{Complexity of climate change and its governance}

The complexity of climate change presents unique governance challenges. Resch et al. (2017, p. 23) drawing on learnings from the UK-aid funded Action on Climate Today (ACT) programme, highlights the importance of achieving the right balance between mainstreaming and concentration when assigning responsibility for adaptation within government. "Planning and budgeting is an inherently sectoral process in governments. Budgets are compiled, appropriated and executed by ministries, departments and agencies, through an organisational landscape of government that tends to be highly static. In contrast, climate change is cross-cutting; its effects are registered across a broad range of sectors and the responsibility for adaptation is similarly diffused throughout government" (Resch et al., 2017, p. 23). There is hence a challenge in reconciling a cross-cutting priority with the organisational structure of sectoral plans and budgets.

\section{Multiple scales of governance and political institutions}

The complexity and multi-level nature of climate change requires governance systems able to manage and resolve conflicts of interests across multiple scales and among diverse policy actors (Di Gregorio et al., 2019, p. 73). However, the governance dimensions of the process of 'mainstreaming' adaptation to climate change ${ }^{2}$ within development is often side-lined in practice, especially in contexts where governance is already a challenge (Gogoi et al., 2017). Major barriers to cross-level communication and collaboration between national and sub-national levels (or multi-level governance interactions) include institutional and political constraints and diverging climate change interests of actors. These constraints are due to power imbalances across governance levels that reflect broader institutional differences between federal and decentralised systems of government (Di Gregorio et al., 2019, p. 73).

\footnotetext{
2 There is a large literature on "mainstreaming" adaptation to climate change, in particular, focusing on the ambiguity in definitions of and frameworks for mainstreaming, identifying critical factors for "effective" mainstreaming, and difficulties in measuring effectiveness and outcomes from mainstreaming efforts (see for example Runhaar et al., 2018; also, Price, 2019 for a summary).
} 
Fraser and Kirbyshire (2017) authored an ODI working paper exploring how political institutions (both formal and informal) can support governance for climate resilience. Their key points include (Fraser \& Kirbyshire, 2017, p. 1):

- Underlying and context-dependent political relationships inform how different approaches to governance for improved resilience to climate shocks and stressors play out in practice.

- The practice of improving governance for resilience may be less about the application of recommendations for particular approaches (such as decentralisation) than an incremental and long-term process of convening willing actors and creating new spaces for engagement between different stakeholders. For international partners to resilience efforts, this approach often challenges conventional modes of operation, and this will need to be addressed.

- In this process, there will be trade-offs that need to be acknowledged, and the approach to such trade-offs agreed between the parties involved.

- The role of different forms of political institutions in shaping governance for resilience merits more investigation, and particularly analysis of the role of political parties and voting systems, executive-legislative relations, constitutional forms, trade unions, bureaucracies and the role of the press.

- There are entry points for engaging with informal political institutions to ensure they work to distribute long-term benefits for all - which also involves recognising how formal and informal institutions interrelate.

- For external actors, there are five principles for action to build governance for resilience: understand political economy and power in the national and local context; broker and facilitate coalitions for change across formal and informal actors; acknowledge trade-offs; focus on process to build effective multi-stakeholder collaboration, rather than technical outputs; and invest in long-term efforts to build trust and engagement.

Another learning review from the ACT programme highlights the role that "policy entrepreneurs" can have in navigating the political complexity of both formal and informal systems of governance to influence adaptation mainstreaming processes (Tanner et al., 2018). Formal institutions are those such as the written constitution, laws, policies, rights and regulations enforced by official authorities, whereas informal institutions refer to the (usually unwritten) social norms, customs or traditions that shape thought and behaviour in a society (Unsworth, 2010 cited in Tanner et al., 2018 , p. 5). It is now thought that informal interactions may be as important as formal governance in determining whether mainstreaming is successful. Policy entrepreneurs work in policy-making arenas to promote policy change, through brokering, advocacy and networking to influence policy. Tanner et al. (2018, p. 1), using empirical examples from the ACT programme in South Asia and building on previous political science literature, create a typology of influencing strategies that includes:

- Stories and narratives - using simplified stories that help decision-makers make sense of complex realities, including by linking climate action to development objectives;

- Rapport and trust - building trust in the programme and its staff and the advice being offered;

- Cheerleaders and champions - nurturing and rewarding leaders and leadership; 
- Advocacy and networking - harnessing and developing networks on adaptation inside and outside government;

- Downstream implementers - influencing action on the ground by working with those who actually implement, rather than set, policy.

They argue that "drawing on these examples and foregrounding the importance of informal and tacit strategies for policy influence can help others who are designing and providing technical assistance to support national and sub-national governments to mainstream adaptation into their policies" (Tanner et al., 2018, p. 1). The influencing strategies can feed off one another, but there can also be trade-offs. For example, reaching out to downstream implementers may take a great deal of time and effort, and reduce the chance of nurturing high-level champions (Tanner et al., 2018, p. 7). The authors also emphasise the need for a thorough understanding of the changing policy context, especially locally, to successful implement some of the strategies discussed.

\section{The importance of political-economy}

Practitioners accept that it is critical to conduct a political economy analysis before engaging at the country level in any type of development policy (it is considered "politically smart" (Whaites, 2017)) - but many argue that this is even more critical for climate policy as it requires systemic transformations involving an array of different actors, uncertainty, and complexity (Worker, 2017, p. 3). Understanding the political-economic dynamics of previous policy reform attempts can help reveal stakeholder dynamics, interests, and, potentially, new ways of building political support (Worker \& Palmer, 2021, p. 10; see also Price, 2019 and 2021b). However, it has been noted that there is little direct evidence about thinking and working politically in climate and environmental governance (Laws \& Marquette, 2018, p. 19). Furthermore, of the literature there is on the political-economy of climate change, most has focused on carbon pricing and the electricity sector, fossil fuel subsidies, or effective institutional governance, less focuses on adaptation (Walker \& Palmer, 2021).

Learnings from the ACT programme highlight the importance of engaging with the political economy of climate finance policy and governance contexts (Resch et al., 2017, p. 24). For example, ACT first actively maps "key influencers" across each governance context in which it is operational, to determine who will be crucial in helping it achieve its goals on accessing and mainstreaming climate finance. Second, ACT undertakes a programme-wide political economy context assessment exercise on an annual basis. This allows the programme to ascertain any shifts in the political or governance contexts, permitting course correction through adaptive management. Third, ACT staff have found that it is vitally important to align with prevailing policy narratives in different governance contexts to secure action on climate finance and action. This means that, many times, the initial conversations between ACT and different governments are focused not on climate change at all but on other issues such as economic growth, disaster risk reduction, private sector engagement etc. Fourth, ACT's work on climate finance has received traction as it actively desists from imposing external priorities on governments and instead focuses on generating demand for support on accessing and managing climate finance from within. This is made possible by ACT staff developing strong relationships of trust with governments and through the institution of formal flexible finance streams. Building bridges into these institutions can take time (Resch et al., 2017, p. 24). 
For example, Schmitz (2016) provides an entry point for understanding who has driven or obstructed renewable energy policies in the rising powers of China, South Africa, India and Brazil. Although not specifically about adaptation, the paper provides insight into the political economy of how path dependencies on fossil fuels can be avoided or diverted to low carbon alternatives. In all of the cases, cross-sectoral alliances were critical to overcoming political opposition. Schmitz (2016) finds that even though the evidence is patchy on how alliances are organised and operate, evidence that they matter in addressing collection action problems is strong. In most cases, climate was viewed as a co-benefit, with the problem framed around other issues such as energy access and security, new industries, jobs.

\section{Accountability mechanisms in climate change framework laws}

A recent Grantham Research Institute policy insight by Higham et al. (2021) examines the elements that can be built-in to climate change framework laws to specify accountability for the implementation of the core obligations contained within those laws. Accountability mechanisms in climate change framework legislation are necessary conditions for building trust between and within nations, providing clarity about the roles of the different actors involved in legislating and implementing climate policies. To date there has been no comprehensive review of the mechanisms by which climate framework legislation may create processes to ensure that actors responsible for their implementation are made accountable for progress. This policy insight aims to bridge that gap. Although definitions of accountability systems are not uniform, the brief highlights four important "accountability elements" that should be built-in to any accountability system or regime created through legislation.

The four elements can be identified by asking the following questions (Higham et al., 2021, p. 1):

(i) What? What obligations are created? What are actors required to do?

(ii) Who? Who is accountable to whom? Does the law specify who is responsible for fulfilling obligations and to whom that responsibility is owed?

(iii) How? How is compliance assessed? Does the law specify the process for determining compliance?

(iv) What next? What happens in the case of non-compliance? Does the law specify what happens? What are the penalties for failing to meet obligations or processes for correction?

The brief argues that "there is an important distinction to be made between assessing compliance and assessing effectiveness. Legislators should strive to ensure that good climate change framework legislation will be subject to processes by which both compliance and effectiveness can be assessed" (Higham et al., 2021, p. 1). Hence, accountability mechanisms will only fulfil their purpose if:

- stakeholders have sufficient technical and financial resources to fulfil the necessary oversight functions;

- the law is appropriately drafted to suit the existing national culture; and

- there is a strong rule of law in the country to guarantee that processes for assessing accountability are followed. 
The policy insight reviews 43 climate change framework laws around the world to assess the level of integration of the four accountability elements, in relation to critical functions of framework laws. Detailed findings are given in the brief, but in summary they found (Higham et al., 2021, pp. 2-3):

(i) What obligations are created? The design of clearly assigned time-bound, and detailed obligations is key to ensuring their enforceability.

(ii) Who is accountable to whom? In developing legislation concerning public accountability relationships, it is vital to ensure that the provisions creating accountabilities between parties do so in a way that is as transparent as possible. Most existing climate change framework laws focus on creating accountability relationships between the executive and other institutions of the state, which can reinforce accountability to the general public.

(iii) How is compliance assessed? There is limited detail regarding the procedural elements of accountability processes, and lack of detail regarding the standards to which different actors are to be held.

(iv) What happens in the case of non-compliance? This is the least well-addressed accountability element in the laws reviewed. Only around half of the countries specified penalties or corrective actions where obligations are determined not to have been met. Many of the accountability processes currently rely on trust-based systems like reporting and disclosure, where reputational damage or loss of public support is assumed to be the primary risk to non-compliant entities.

Citizen councils or platforms for climate action are spaces created by the authorities or by public initiative to strengthen citizen or civil society organisation (CSO) participation in climate change issues. They can also become formal spaces (UNICEF, 2020, p. 15). For example, in its first Nationally determined contribution (NDC), Costa Rica committed to creating a Consejo Consultivo Ciudadano de Cambio Climático [Citizen Climate Change Council- 5C]. This is a deliberative space that aims for participation in designing and implementing climate policy. Chile has a Sociedad Civil para la Acción Climática [Civil Society for Climate Action-SCAC] made up of organisations from different sectors aiming to raise awareness about the climate crisis and propose solutions from a civil society perspective. The effectiveness or impact of either of these platforms is not clear.

\section{Climate finance and green public financial management (PFM)}

\section{Green public financial management (PFM)}

Green PFM means to gradually adapt existing PFM practices to make them environment and climate sensitive. Green PFM is a notion akin to green budgeting, but with a wider scope, as it explicitly considers broader PFM functions that might go beyond the scope of the budget (such as coordination with other public sector entities or fiscal transparency) (Gonguet et al., 2021, p. 2). It also bears a strong resemblance to other types of so-called priority-based budgeting approaches, such as gender-sensitive budgeting. Green PFM does not require a novel approach to PFM, rather an adaptation of existing PFM processes and tools. 
Green PFM has been gaining increased attention in the last few years, with a number of publications and lessons learned papers. For example, the World Bank's (2014) Policy Note Moving Toward Climate Budgeting provided a first tentative blueprint for the integration of green budgeting principles in the budget cycle. A background report for the Global Commission on Adaptation (Allan et al., 2019) explores the role of domestic budgets in financing climate adaptation. 2021 also saw the publication of a number of detailed guidance notes, including an IMF Staff Climate Note (Gonguet et al., 2021), an updated World Bank (2021) guide on budget tagging and a UNDP (2021) guidance note on budgeting for climate change ${ }^{3}$. However, green PFM practices remain nascent in most countries. Gonguet et al. $(2021$, p. 5$)$ suggest this scarcity of green PFM practices could be due to "a lack of awareness, limited appetite for changes to the budget process, and, in the case of [low-income developing countries], pre-existing PFM capacity limitations and uncertainty as to where to start." This also highlights that although "there is empirical evidence of the effectiveness of other types of priority-based budgeting in improving outcomes..., given the relatively recent implementation of green PFM practices, there is only anecdotal evidence of their actual impacts, mostly on outputs" (Gonguet et al., 2021, p. 4). Furthermore, to date, climate budget tagging efforts have been dependant on technical assistance (usually from UNDP, World Bank, or FCDO), and the sustainability of efforts beyond the life-cycle of these engagements remains to be seen (Allan et al., 2019, p. 25). Gonguet et al. (2021, p. 16) also notes that such green PFM reform "can be a long journey."

There is also an important and growing literature on the decentralisation of climate funds (also see Price, 2021a on CSO funding mechanisms). Devolving climate finance to the local level is seen as giving local people agency over decision making about resilience investments, especially the poorest and most marginalised. Although, the devolution of climate finance from major funds appears small and there is "an urgent case for new or improved global climate financing mechanisms to provide patient climate finance over a minimum of ten years to the local level" (Patel et al., 2020, p. 47). Due to time limitations this rapid review is unable to go into detail on these issues.

\section{General climate adaptation entry points in the budget cycle}

A 2019 background report for the Global Commission on Adaptation explores the role of domestic budgets in financing climate adaptation (Allan et al., 2019). The report highlights a number of challenges with domestic financing for climate adaptation, but also argues how governments have pursued varied and innovative means of augmenting budgetary resources for adaptation. They summarise a number of prominent entry points that span all stages of the typical budget cycle ${ }^{4}$, and serve to address the shortcomings in prevailing domestic budget processes that result in systematic underinvestment in adaptation. These interventions are designed to make PFM processes more responsive to adaptation needs, with the ultimate objective of leading to better adaptation outcomes from public expenditure. Table 1, taken from

\footnotetext{
${ }^{3}$ UNDP's (2021) Guidance Note on budgeting for climate change consolidates learnings from various frameworks and tools, with a particular focus on Medium-Term Budgeting. These tools include Climate Expenditure and Institutional Review (CPEIR), Climate Change Budget Integration Index (CCBII), PEFA Climate Module, Climate Change Performance Index (CCPI), Climate Change Screening and Appraisal (CCSA) tools, Climate Change Policy Assessment, etc. (UNDP, 2021, p. 13).

${ }^{4} \mathrm{NB}$ : Most of the guidance notes referenced here are based on a similarly structured budget cycle. For example, Gonguet et al. (2021) also take the typical budget cycle as a four-step cycle, anchored by a legal framework.
} 
Allan et al. (2019), summarises these prominent entry-points for each stage of the typical budget cycle.

Gonguet et al.'s (2021, p. 11) brief discussion of control and audit mechanisms in PFM systems (stage 4 of the budget cycle) highlights that:

- Internally, line ministries and agencies should monitor and assess the climate outputs attached to their budget actions. Internal audit or inspection bodies, especially within the MoF, can also adopt a climate focus in their work programme.

- Externally, the country's SAI could assess compliance of government programmes/projects and transactions with the climate-related objectives and requirements, either by undertaking a dedicated audit (for example, Bangladesh's climate performance audit methodology) or as part of existing audit types (for example, Canada). The parliament, as the main oversight body, could examine the reports of SAI and related evaluation reports on green or climate strategies, and ask for corrective measures in case of any deviation from the approved target (for example, Nepal and Pakistan).

Table 1 - Prominent examples of climate budgeting initiatives

\begin{tabular}{|c|c|}
\hline Budget cycle phase & Climate adaptation entry-point \\
\hline \multirow[t]{5}{*}{ Budget preparation } & $\begin{array}{l}\text { Public investment appraisal: Climate change considerations can be } \\
\text { incorporated into a variety of different public investment appraisal } \\
\text { techniques, from relatively simple multi-criteria checklists to more robust } \\
\text { cost-benefit analyses. This is often termed 'climate change impact } \\
\text { appraisal' }(\mathrm{CCIA}) \text {. }\end{array}$ \\
\hline & $\begin{array}{l}\text { Macroeconomic forecasting and fiscal sustainability analysis: In some } \\
\text { countries there has been an effort to incorporate climate change } \\
\text { considerations into macroeconomic forecasts and fiscal sustainability } \\
\text { analysis. }\end{array}$ \\
\hline & $\begin{array}{l}\text { Annual budgeting frameworks: Ministries, in their budget submissions to } \\
\text { the ministry of finance, will often be required to prepare an annual } \\
\text { budgeting framework which sets out the key ministerial programmes, and } \\
\text { often key performance indicators (KPIs) for each ministry. In relevant } \\
\text { ministries, adaptation needs can be reflected in these documents and } \\
\text { climate-related KPIs can be included. }\end{array}$ \\
\hline & $\begin{array}{l}\text { Medium-term expenditure frameworks: These involve laying out } \\
\text { allocations to spending agencies over a three- to five-year period, as } \\
\text { opposed to just a single year. Climate change can be introduced into this } \\
\text { framework, giving certainty and predictability to agencies, while allowing for } \\
\text { alignments with other priorities along the way. }\end{array}$ \\
\hline & $\begin{array}{l}\text { Budgeting guidelines: The government's budget circular can be adjusted, } \\
\text { or an additional circular prepared, to require line ministries to prioritise } \\
\text { climate adaptation programming and/ or to explain how their submitted }\end{array}$ \\
\hline
\end{tabular}




\begin{tabular}{|c|c|}
\hline & $\begin{array}{l}\text { programmes contribute to adaptation and how they are linked to the } \\
\text { national strategies around adaptation. }\end{array}$ \\
\hline \multirow[t]{3}{*}{ Budget approval } & $\begin{array}{l}\text { Budget hearings: Ensuring adaptation is an agenda item or consideration } \\
\text { in budget hearings conducted by the ministry of finance can be achieved by } \\
\text { adding it to the official budget appraisal criteria and by ensuring that those } \\
\text { engaged in the negotiations are adequately sensitised. }\end{array}$ \\
\hline & $\begin{array}{l}\text { Budget statements / speeches: Some countries have succeeded in } \\
\text { including climate adaptation in the budget speech made by the Minister of } \\
\text { finance, where they present the resource allocation priorities of the } \\
\text { government with their overall rationale and political context. }\end{array}$ \\
\hline & $\begin{array}{l}\text { Parliamentary scrutiny of the budget: Ensuring the parliament has the } \\
\text { information and capacity to scrutinise the government budget from a } \\
\text { climate change perspective can be an important means of ensuring } \\
\text { lawmakers hold the government to account in regard to meeting its } \\
\text { financial commitments related to climate change. }\end{array}$ \\
\hline \multirow[t]{4}{*}{$\begin{array}{l}\text { Budget execution, } \\
\text { monitoring and } \\
\text { reporting }\end{array}$} & $\begin{array}{l}\text { Cross-committee engagement: Some legislatures have climate change } \\
\text { committees, while the core of budget examination is typically done by } \\
\text { finance or budget committees. Cross-committee engagement can } \\
\text { strengthen scrutiny of climate-related budgets. }\end{array}$ \\
\hline & $\begin{array}{l}\text { Expenditure tracking, including through the use of a budget tagging } \\
\text { system: A major trend in recent years has been the introduction of a } \\
\text { climate budget tagging or scoring system, as a tool for the monitoring and } \\
\text { tracking of climate-related expenditures in the national budget system. }\end{array}$ \\
\hline & $\begin{array}{l}\text { Performance indicators: With the spread of performance-based } \\
\text { budgeting, some countries are seeking to ensure indicators are defined } \\
\text { which capture the adaptive performance of relevant programmes. }\end{array}$ \\
\hline & $\begin{array}{l}\text { Processes for cash management, and managing budget revisions: It is } \\
\text { not uncommon for implemented budgets to vary considerably from planned } \\
\text { budgets, and a key entry point for impacting on adaptation spending is to } \\
\text { ensure that in the face of funding shortfalls adaptation programmes enjoy } \\
\text { some degree of prioritisation or protection from cuts. Such measures } \\
\text { include ring-fencing particular spending programmes. }\end{array}$ \\
\hline \multirow[t]{2}{*}{$\begin{array}{l}\text { Accountability and } \\
\text { ex-post oversight }\end{array}$} & $\begin{array}{l}\text { Parliamentary scrutiny: Parliamentary climate change committees and } \\
\text { sector committees in key adaptation-related sectors can play a role in } \\
\text { scrutinising government reports to determine whether adaptation-related } \\
\text { targets have been met. }\end{array}$ \\
\hline & $\begin{array}{l}\text { Performance audits: Creating an increased role for SAls, both in terms of } \\
\text { quality assuring the climate budget reports and conducting performance } \\
\text { audits which consider performance from an adaptation perspective, are } \\
\text { emerging entry points. }\end{array}$ \\
\hline
\end{tabular}




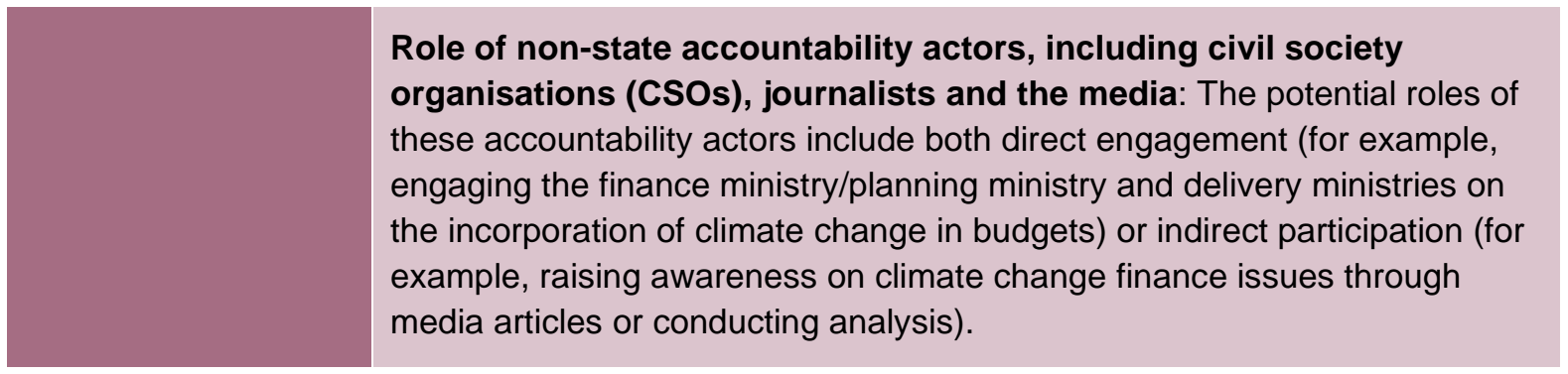

Source: Allan et al., 2019, pp. 3-4 reproduced under CC BY 4.0

\section{CSOs roles in accountability of climate finance}

In a World Resources Institute (WRI) working paper, Krishnan (2020) discusses how CSOs provide accountability for climate adaptation finance, especially at the local level, and highlights how CSOs' capacities can be built to play these critical roles. It draws from the Adaptation Finance Accountability Initiative's (AFAI II) experiences in Ethiopia and Uganda, and also builds on lessons learned from similar efforts in Bangladesh, Kenya, and the Philippines. Experiences from the AFAI II show that with tailored support, capacity building and training, CSOs can fulfil these necessary functions:

- Continually raise awareness and knowledge of climate-related issues within local governments and communities;

- Facilitate community-government dialogues on adaptation and resilience priorities to influence resource allocations;

- Support government efforts to devise climate finance tracking methodologies that enable more consistent resource tracking; monitoring policies and budget allocations; and

- Use this evidence to advocate for inclusion of community priorities.

Another important consideration highlighted by UNDP and IBP (2018) is that CSOs often rely on indirect pathways of influence, as direct, formal influence opportunities are often limited. Hence, media and journalists are often key players in the climate change finance accountability landscape given these indirect pathways of influence. Lessons learned from formulating the CSO capacity-building strategy in the AFAI II programme highlighted by Krishnan (2020, pp. 11-12) include:

- Leveraging CSO partners and their networks: Early scoping and the assessments identified core CSO partners in both countries as anchors for the capacity-building effort. These already had established programs of work that were directly connected or adjacent to the climate finance discussions, thus allowing the capacity-building efforts to build on an existing foundation of knowledge and relationships with communities, other CSOs, and the government.

- Enabling engagement with public officials: The capacity-building programme also needed to sensitise and engage government agencies and officials to pave the way for greater opportunities to engage on climate finance-related issues and promote longerterm collaboration. In both countries, the strategy leveraged the core CSO partners' established links with different government agencies. Based on the assessments, the 
partners in both countries were also aware of limited capacities within government agencies.

- Reiterative training and engagement: The programme's core CSO partners were primarily responsible for designing and delivering training to their peers. Training was delivered in a series of progressive modules that built on each other, with a refresher of basic concepts in each module. Participants were asked to commit to attending all the training in the series; however, there was no official enforcement mechanism other than concerted follow-up from the core partners. Training focused on a range of issues, one being developing common definitions for what constituted adaptation and qualified as climate finance, particularly adaptation-related finance. This was key in developing a common framework for engagement.

- Conducting Reiterative Political Economy Assessments: Once undertaken, these political economy assessments within countries were never considered complete. They were iteratively updated as the country contexts for accountability and climate finance changed.

- Partnering with Domestic Teaching Institutions: As part of the capacity-building strategy and CSOs' desire to sustain and expand their programme reach, the capacitybuilding strategy looked for opportunities to connect CSO partners with universities or research institutions that trained the next cohort of professionals. This provided another way of raising awareness of domestic climate-related priorities, processes, and finance.

A keynote paper from the Inclusive Budgeting and Financing for Climate Change in Africa Programme (IBFCCA) focuses on climate finance accountability in Africa, taking lessons from Ghana and Uganda specifically (CABRI, 2021c). It finds that climate budget systems and associated climate finance accountability are just emerging in Ghana, Uganda and most other African countries. They are most robust in upstream policy setting and planning phases of the public resource cycle, and at the central level; accountability for climate finance reaching the local level and those who are most vulnerable is still weak. Accountability is significantly hampered by lack of information and underdeveloped capacities; "the further away from the centre, and the closer to vulnerable communities, the less resourced the climate finance accountability system is and the weaker the capacities" (CABRI, 2021c, p. 6). In particular, the paucity of climate finance and spending information in African countries is a binding constraint on engagement by parliamentary, civil society and media actors (CABRI, 2021c, p. 6).

\section{Barriers and challenges to adaptation budgeting}

Efforts to monitor public climate change spending and the prioritisation of adaptation in domestic budgets face several significant challenges and barriers. These include (Bird \& Granoff, 2016, p. 5; Allan et al., 2019, pp. 12-16):

- Definition ambiguity: Difficulties around the definitional ambiguity of climate change actions and hence financing, especially for adaptation finance (Bird \& Granoff, 2016, p. 5; Allan et al., 2019, p. 12).

- Uncertainty and complexity: The complexity of climate change science makes it challenging to derive salient and directed policy implications. Challenges in quantifying the negative economic consequences of climate change and the positive economic 
returns to investment in adaptation make it hard to 'make the case and win the argument' for financing adaptation (Allan et al., 2019, p. 12).

- Reporting and data issues: In many countries a varying proportion of public funds do not pass through the national budget and therefore lie outside its reporting systems. Records of recurrent spending are frequently insufficiently detailed to allow the climate change relevant component to be identified (Bird \& Granoff, 2016, p. 5).

- Lack of capacity and communication: Actual expenditures (as opposed to the budget estimates) are often not readily available. As a result, the identification of climate change relevant finance within public expenditures has not been institutionalised in most countries. The fact that climate change risks are not well communicated or widely understood compounds an existing challenge around weak capacity for integrating risk into budgeting (Bird \& Granoff, 2016, p. 5; Allan et al., 2019, p. 15).

- Lack of awareness: There continues to be a deficit in awareness among developing country governments (and central finance agencies in particular) that adaptation is an issue which should be mainstreamed across the domestic budget process, as part of the pursuit of broader development goals (Allan et al., 2019, p. 15).

- Institutional barriers: A lack of appropriate institutional leadership is also something which has hampered the mobilisation of domestic finance for adaptation. Institutional coordination is also a challenge. The governance of adaptation is a diverse responsibility which should fall across multiple institutions; however, ministries have different (and sometimes competing) priorities, jurisdictions, and constituencies, which complicate the manner in which institutions should work together to achieve adaptation objectives. This comes to the fore in PFM systems, which tend to mirror the institutional setup of government, and so do not comfortably accommodate cross-sectoral concerns. Hence, mainstreaming adaptation means working in opposition to these basic governing principles of PFM systems (Allan et al., 2019, pp. 16).

- Political and governance barriers: Climate change adaptation often competes with other development objectives for scarce fiscal resources, and it is not uncommon for political classes to prioritise more expedient, short-term issues. This relates to the uncertainty and complexity of climate change, as well as the divergent timeframes between adaptation returns and a typical election cycle. Compounding this is the welldocumented reality that there are higher political gains to be had from disaster response compared to investment in prevention (Allan et al., 2019, p. 17).

Furthermore, recent research has identified specific barriers which prevent accountability mechanisms and actors from fulfilling their functions in relation to climate finance (Allan et al., 2019, p. 17):

- Lack of awareness among accountability actors on how the impacts of climate change threaten development priorities.

- Technical capacity gaps - among CSOs and journalists there tend to be groups that work on climate change and groups that work on budget issues, with minimal interaction between them.

- Lack of meaningful and detailed information on the government's adaptation spending, related to challenges around fiscal transparency as a whole. Where the 
government does issue publications on the public expenditure, the information is often highly aggregated and not in a format which these actors can interrogate.

- Relatedly, a lack of a clear, agreed definition of what constitutes climate-related expenditures. Even in countries where the government is reporting on its climate expenditures (e.g. Nepal), if the methodology used to determine what "counts" as climate change is not well-understood or accepted, the results may not be deemed credible.

- Minimal opportunities for CSOs to engage in the budget process in general, and therefore to influence how funds are allocated for adaptation and other purposes.

- Minimal engagement of supreme audit institutions (SAls) on climate finance issues.

- Extensive use of earmarked funds for financing climate action - such funds lie outside of core formal accountability systems, and lack adequate compensation transparency.

\section{Lessons learned and guiding principles for green PFM reform}

\section{Using the existing budget cycle and legal framework}

Gonguet et al. (2021) argue that the legal framework of a country plays a key role in embedding climate objectives into PFM, as it underpins the budget cycle and PFM practices. Hence, the effectiveness of the green PFM practices ultimately depends on their being grounded in law. UNDP's guidance note (2021, p. 13) echoes the need to align measures with the budget cycle and also to ensure flexibility in the reforms approach; emphasising the need to build on existing systems, ownership, policies and commitments. ${ }^{5}$ Countries with a strong performance budgeting system might seek to integrate performance objectives related to national environmental and climate goals. Whereas countries with a well-founded expenditure reporting and review process may wish to focus on considering the impact of measures towards climate goals alongside considerations of effectiveness and efficiency (UNDP, 2021, p. 13).

Gonguet et al. (2021) highlight a number of existing diagnostic tools that can help governments to identify green PFM reform priorities and design a realistic reform strategy, including the upcoming IMF's Climate Macroeconomic Assessment Program, the UNDP's Climate Public Expenditure and Institutional Review $(\mathrm{CPEIR})^{6}$, or the climate-responsive Public Expenditure and Financial Accountability.

A keynote paper summarising findings from the first IBFCCA Peer Exchange, which brought together officials from ministries of finance (MoFs) across Africa, highlights that the most widespread areas of climate-responsive PFM in African countries relate to upstream budget processes, in particular strategic planning and budget tagging/tracking (CABRI, 2021a, p. 5). It estimates that 40 African governments have produced a budget strategy or plan which relates

\footnotetext{
5 Strengthening gender responsiveness of the climate-sensitive planning and budgeting is also an important consideration and issue (see UNDP, 2021, p. 47).

${ }^{6}$ CPEIRs are mentioned in much of the literature. According to Allen et al. (2019, p. 14) "it is is a systematic qualitative and quantitative analysis of a country's public expenditures and how they relate to climate change. Using a definition of climate change and adaptation which is tailored according to each country policy context... Since they were first piloted in 2010/11, CPEIRs have been conducted in over 20 countries."
} 
specifically to climate change, while another five governments have them in development. (Intended) Nationally Determined Contributions (I/NDCs) have proven to be a useful trigger for integrating climate change into PFM reforms. For example, the Government of Nigeria explained how its Sovereign Green Bond was an innovative means of meeting domestic financial commitments set out in its NDC (CABRI, 2021a, p. 6).

\section{Ensure that the basic elements of a functional PFM system are in place}

Gonguet et al. (2021, p. 13) argue that several prerequisites are necessary for successful green PFM reforms, and "greening" PFM systems only makes sense if the basic elements of a functional PFM system are already in place. Priorities in this respect are ensuring basic financial compliance, with a robust budget preparation and budget execution processes, ideally underpinned by a functional financial management information system.

\section{Strong leadership of the Ministry of Finance (MoF) and clear linkage with the overall PFM reform agenda}

While green PFM reforms constitute a whole-of-government undertaking, the MoF as the custodian of public resources should be the primary driver of reforms (Gonguet et al., 2021, p. 14). This central role of the MoF also means that it can assess what changes in budget cycle are realistically possible without hampering the overall effectiveness of PFM processes or falling into a "complexity trap." Green PFM reforms should also be integrated with the existing PFM reform agenda to ensure they are mutually reinforcing, whatever the level of capacity. Moreover, managing green PFM reforms would draw upon the same set of skills as the design and implementation of other PFM reforms (Gonguet et al., 2021).

In terms of institutional engagement, climate budget tagging usually requires the engagement of the ministry of finance, as the overall controller of the budget system; however, it is often spending agencies (as the parties most familiar with the details of budget programmes) that apply the tags. Involving them in this way can ensure that the quality of investments (from a climate change perspective) improves over time (Allan et al., 2019, p. 24). Allan et al. (2019, p. 24) also find that a primary benefit of climate budget tagging has been in providing an entry point for engaging ministries of finance on climate issues, and from a line ministry perspective as a means of attracting additional budget adaptation activities.

\section{Smart sequencing of reforms}

Gonguet et al. (2021, p.15) emphasise the need for an appropriate sequencing of green PFM reforms in a country, with action plans that identify the key stakeholders in charge of each action and a precise sense of the timeline for their implementation. It is logical for governments to start with green PFM reforms along the upstream part of the budget cycle, before moving downstream. It can be beneficial to roll out green PFM reforms gradually, starting with a few pilot ministries or agencies or with a limited set of new practices to ensure their operability. For example, countries such as Bangladesh, Indonesia or Nepal have started implementing green budget tagging in a small number of pilot ministries with relatively high "green" stakes before a wider rollout. 
An important starting point -readily overlooked- is to clearly state the expected objectives of the proposed system. This will help determine, for example, what stage of the budget cycle should be given attention in any public expenditure analysis (Bird \& Granoff, 2016, p. 8).

\section{Real political ownership and clearly defined roles and responsibilities}

Strong political backing and ownership in green PFM reform is even more necessary than for a standard PFM reform agenda (Gonguet et al., 2021). Climate change is cross-cutting, involving multiple stakeholders, and creating challenges for a collaborative effort. Political willingness is hence critical. Identifying key stakeholders for the climate change integration reform process and articulating clear institutional roles and responsibilities is vital (see MoF point above). Coordination mechanisms amongst the Executive will promote cohesiveness and facilitate the implementation of the climate change integration agenda (UNDP, 2021, p. 13).

\section{Good communication to stakeholders}

Gonguet et al. (2021, p. 16) highlights the need for good communication on the progress of green PFM reforms to ensure buy-in from all stakeholders and manage expectations. Communications and gathering feedback early on is important to gradually build awareness and buy-in among internal and external stakeholders. The MoF can make use of a broad spectrum of communication tools to provide updates on the reform. It is also important to generate and tailor information to different audiences and decision makers' needs in formats they can use (World Bank, 2021, p. 9).

\section{Climate budget tracking should be seen as a first step not an end in itself}

Climate budget tagging has emerged as a tool for monitoring and tracking climate-related expenditures in the national budget system. Allan et al. (2019, p. 24) explain that "Climate budget tagging works by flagging budget lines that are relevant to climate change adaptation/mitigation, and recording budget allocations and/or expenditures which are made against those lines, to provide an overall picture of climate-related spending." There are three major design elements to climate budget tagging methodologies: definition of climate-relevant expenditure; definition of appropriate coverage; and estimation of climate-relevant spending. Since the introduction of the first systems in 2012, 19 national and subnational governments have developed climate budget tagging methodologies (World Bank, 2021, p. 7). The principal reported benefits of the application of climate budget tagging are awareness raising and improvements in transparency and accountability. However, it is difficult to determine tagging's impact on budget allocations and decision making and evidence remains limited to draw definite conclusions (World Bank, 2021, p. 8).

Budget tracking should be viewed as a first step in a performance management system, which also requires an accompanying assessment of the outputs, outcomes, and impacts of relevant programmes (Allan et al., 2019, p. 24). The magnitude of climate budgeting is a poor proxy for climate outcomes; budget tracking can only address the financial inputs of climate change relevant actions, which cannot measure the impact of such spending. Expenditure analysis should therefore be seen as one tool that can lead to a deeper understanding of national climate change strategies. Other types of financial, economic and climate analysis should complement 
the budget tracking tool to evaluate climate finance effectiveness (Bird \& Granoff, 2016, p. 9). Some countries have used tagging formation to directly inform budget decisions (such as in the Philippines) or the design of programmes (such as in Odisha); however, in other locations the value added is less evident (Allan et al., 2019, p. 24).

Some key design considerations in climate budget tagging include:

- Define the objectives of the climate budget tagging initiative and consider alternatives. This will inform decisions on whether to embark on climate budget tagging and the design of the tagging system. In some circumstances, mainstreaming climate change may be a preferred alternative (World Bank, 2021, p. 9).

- Define the policy scope of the tagging methodology. Tagging can support multiple policy objectives. However, the multiplication of tags increases implementation costs and can hinder prioritisation (World Bank, 2021, p. 9).

- Tagging of budget allocations is more common than tagging of actual expenditures, but, given that expenditures can depart significantly from allocated amounts, for a meaningful assessment, both are required (Allan et al., 2019, p. 24).

- There is a trade-off between the degree of accuracy and the level of effort and capacity required. This relates to the level of expenditure which is tagged (more granular approaches, i.e. tagging at activity or activity component level, might be more accurate but can be highly labour intensive), and the weighting methodology (approaches that draw on cost-benefit analyses being more robust but more demanding in terms of capacity and data) (Allan et al., 2019, p. 24).

- The lack of consensus or standardisation around climate change relevance weighting is a cause of confusion and prevents cross-country comparison in climate budget tagging. Some experts consulted for the Allan et al. (2019) paper felt it would be pertinent to wait for consensus on this issue before countries invest more in budget tagging, others felt the variation in country approaches should be nurtured alongside peer-to-peer learning, and that cross-country comparison matters less than temporal trends within countries.

\section{Lessons and insights on transparency and accountability in green PFM}

\section{A well-functioning accountability ecosystem is needed}

The UNDP (2021) guidance note builds on lessons learned from previous UNDP work in Nepal, the Philippines, Bangladesh and India (UNDP \& IBP, 2018). The UNDP and IBP (2018, p. 22) report highlights that a well-functioning "accountability ecosystem" is needed in which state (legislatures and SAIs) and non-state (CSOs, media, academia, and citizens) accountability actors engage with one another and the executive to improve climate change-related budget policies, monitor execution, and contribute to oversight.

The IBFCCA keynote paper highlights the following interdependent elements as being key to the functioning of robust domestic climate finance accountability - although recognises that this ideal 
system is unlikely to exist yet in a coherent and effective way in any country (CABRI, 2021c, p. 12):

- A functional underlying PFM system, that channels resources as appropriated by law to public priorities and to service delivery as targeted, and which can deliver timely and reliable information on the volume and use of public financial flows (from both own and donor sources).

- State accountability actors, such as legislatures and SAls, that have the necessary institutional structures, legal mandates, systems, and human resource capacities to play their legally mandated roles. State accountability actors also include public officials in the executive who have oversight responsibilities in the policy-budget-service delivery cycle.

- Capacitated media and civil society actors, including citizens and their organisations, professional bodies, non-governmental organisations (NGOs) and academia, who are sufficiently organised and active, and have the skills and knowledge to engage the state on its public resource decisions and hold the executive and accountability actors to account.

- The internal and external timely availability of reliable, comprehensive and useful information on resource flows, use and results to empower state, media and civil society accountability actors.

- Effective formal opportunities for engagement and oversight by accountability actors, especially non-state actors, on planned and realised public resource flows, uses and results.

- An established or emerging culture of formal and informal political and technical accountability, in which elected and appointed public actors understand themselves as accountable for the public resource decisions they make, notwithstanding the source of financing, and face consequences when public funds are wasted or diverted.

- Open and transparent climate specific policy and budget measures to ensure that climate finance and expenditures are (i) given appropriate attention in the public resource management cycle, (ii) accounted for in public reports and (iii) scrutinised by public, media, and civil society accountability actors.

\section{Public participation, CSOs and accountability}

CSOs can play an important role in bridging the gap between transparency and accountability by functioning as information intermediaries, as well as by putting pressure on oversight institutions (van Zyl, 2014). Public participation should be encouraged at all stages of the budget cycle, as it helps to strengthen the link between the budget and outcomes for citizens, and also provides an accountability mechanism. Gonguet et al. (2021, p. 11) suggest that "Public participation in the context of green PFM can build on existing mechanisms, including the inclusion of green outcomes in participatory national planning mechanisms and pre-budgeting consultations, or public consultations on social and environmental impacts of the budget."

However, Allan et al. (2019, p. 24) flags that the use of budget tagging results by accountability actors has been minimal to date. Too often the reports are impenetrable for non-technical audiences (although citizen climate budget reports, which attempt to convey key messages in an accessible and visually engaging format, can aid in this respect). In other cases the information 
shared does not give enough detail to support meaningful monitoring by CSOs, or a lack of understanding around the methodology means the results are not deemed credible (Allan et al., 2019, p. 24).

Accountability actors' engagement in climate budget issues is most advanced in South Asia (see next lesson), however, there are a few examples emerging from Africa (CABRI, 2021a, p. 22). Presentations at the first IBFCCA Peer Exchange from CSOs from Bangladesh, Ghana and Uganda illustrated the importance of engaging civil society in the gender and climate budgeting and finance agenda. Some of the key lessons learned across countries include: taking time to develop constructive relationships with government officials; identifying policy gaps and using these as opportunities for entry points; and how communicating through simplified language can help civil society understand the bigger picture. Overall, the engagement with accountability actors around climate budgeting is relatively new for many governments in Africa, and lessons can be taken from looking toward the experiences in Asia (CABRI, 2021b, p. 4).

\section{Comprehensive and uniform reporting practices and definitions and public availability of data for transparency}

Transparency is key for credible green PFM and requires that "the climate commitments, targets, forecasts, costs, outputs, and outcomes be transparently reported and available in a clear and timely manner to the civil society and the public, while giving the public an opportunity to participate in shaping the budget choices" (Gonguet et al., 2021, p. 10). Climate budget tagging can only inform public debate if the information generated is publicly available. Raising awareness among key stakeholders of the purpose of climate budget tagging, the policy objectives that it supports, and how to use climate budget tagging information is also important (World Bank, 2021, p. 9). Climate change budget tagging is possibly more useful for internal government purposes than for public accountability (UNDP \& IBP, 2018, p. 23).

Linked to the previous lesson, UNDP (2021) also notes that ensuring public access to budgetary data is essential to foster accountability. Publicising key budget documents, with performance information, is an easy way for governments to ensure transparency. Citizen's Climate Budgets can be prepared and published, explaining climate expenditure and performance information. Engagement of CSOs and civil society in the process can help the public understand climate change aspects of the government's budgets (UNDP, 2021, p. 43). For example, in Bangladesh, the Climate Budget Report is prepared based on climate data and information in the budgets of relevant Ministries/Divisions to inform Parliamentarians and other stakeholders of the pattern of resource allocation. The Citizens Climate Budget Report is an annual publication presented in simple language and published for a wider audience using infographics. The Government invites CSOs to participate in pre-budget consultations (UNDP, 2021, p. 43). In India, Odisha has started publishing climate budgets for 11 key sectors aligned with the State's climate change action plan, it also engages civil society to comment on pre-budget documents. These are published as part of its regular budget process. However, the extent to which the citizens' engagement influences budget decisions is not clear (UNDP, 2021, p. 43).

It is important to identify all externally funded initiatives and establish uniform reporting practices to give a complete picture of climate-related expenditures (World Bank, 2014). There is also a need for more comprehensive reporting at the sub-national level and among state-owned enterprises (World Bank, 2014). Common definitions of climate-relevant activities and 
expenditures must be aligned with national climate change policies and strategies to avoid confusion and provide a robust picture of investments (World Bank, 2021, p. 9). The lack of a clear and agreed definition of climate change actions and financing is often a stumbling block for adaptation finance accountability (UNDP \& IBP, 2018, p. 23). This was reflected in learning from the AFAI II programme, which found there was the need to agree a common definition for climate-related expenditures for the country, as what counts as adaptation in one region in a country may not be the same as in another region of the same country (Krishnan, 2020, p. 13). Understanding that climate-budget tagging is only the first step in establishing greater transparency and dialogue on climate finance is also key (Krishnan, 2020, p. 14). Undertaking periodic expenditure reviews is also needed to test the alignment of plans and budgets with climate policy goals and impacts on climate outcomes (World Bank, 2021, p. 9).

See also Box 1 below for information on Transparency International's governance standards for climate finance pilot programme.

\section{Inclusion of negative and positive climate impacts of policies}

Budget documentation should include evidence on the positive and negative environmental impacts of fiscal policies, as well as analysis of the fiscal risks related to climate change and natural disasters (Gonguet et al., 2021). Climate budget tagging should also identify and tag activities and expenditures that have adverse climate impacts. This ensures consistency with commitments to the Paris Agreement, allows stakeholders to assess trade-offs, and facilitates debate on sensitive policy issues such as fossil fuel subsidies (World Bank, 2021, p. 9).

However, Allan et al. (2019, p. 24) report the lack of accounting negative investments in country assessments (i.e. spending which is not consistent with climate-compatible economic development, including maladaptation). France is the first (and only) country to tag expenditures on activities that have an adverse impact on the environment in its 2021 budget (World Bank, 2021, p. 24). 


\section{Box 1: Transparency International: Governance standards for climate finance pilot}

Climate finance can be vulnerable to corruption without strong governance standards. Developing and applying standards for how climate finance flows are handled, and how decisions are made in their allocation and delivery, can support climate finance accountability and governance mechanisms. Transparency International (2018) presents a framework to create and assess governance standards for climate finance. The framework evaluates the governance quality of climate finance by looking at the components of financing climate adaptation (planning, accessing, delivering and monitoring effectiveness), combined with key criteria of good governance (transparency, accountability, participation, integrity and coherence). Each of these can then be assessed for four major stakeholder groups (civil society, business, government and international agencies). The overall framework can be modified so that stakeholders can choose their own specific indicators for each standard. Furthermore, various stakeholders can use the same framework as a monitoring and appraisal tool to ensure transparency and hold key actors accountable (Transparency International, 2018, p. 32). The framework is a work in progress and was piloted by Transparency International Bangladesh and Transparency Maldives during 2016 and 2017. Figure 1 provides a summary of the process.

\section{Figure 1: The process of producing national climate finance governance standards}

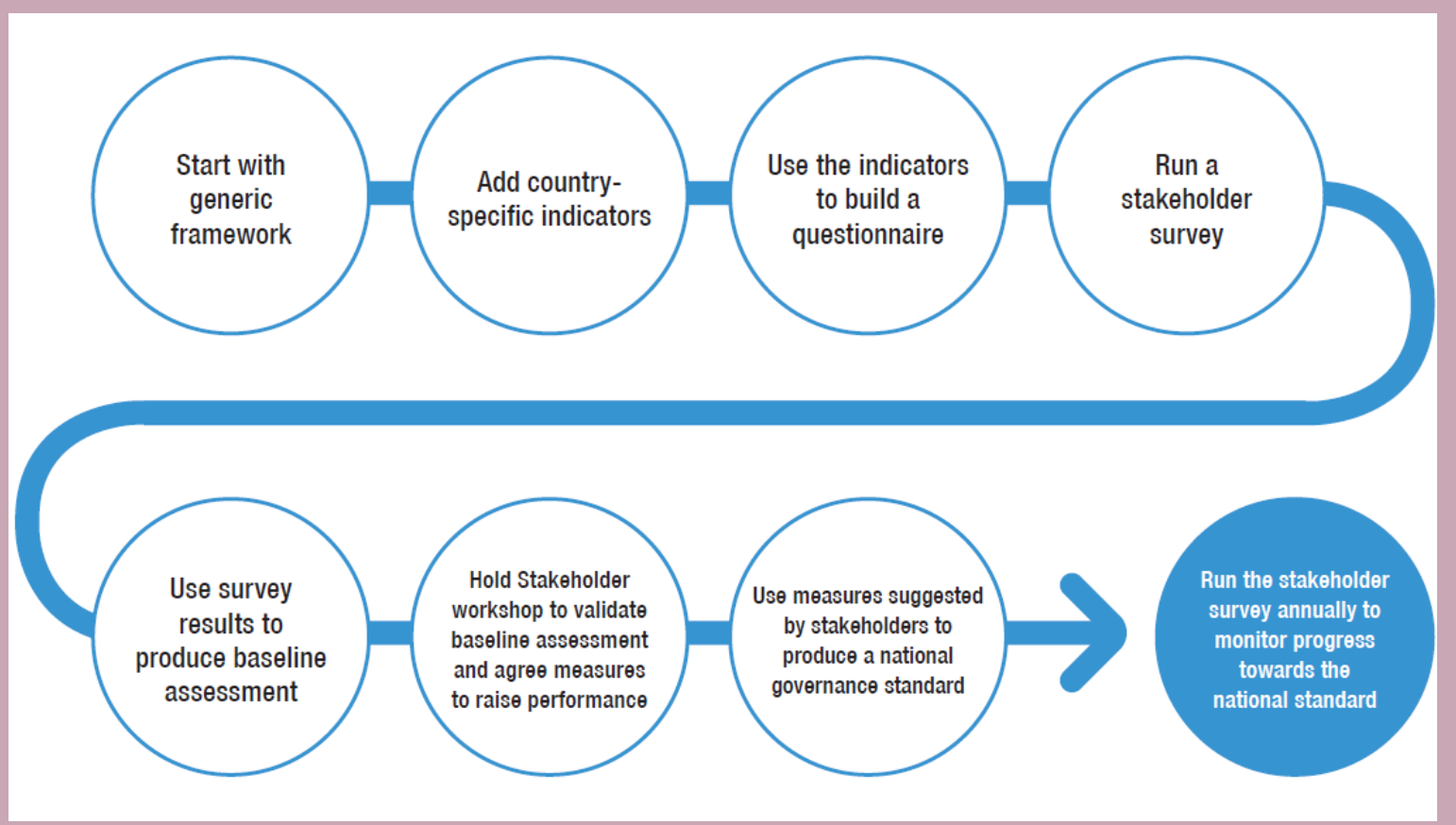

Source: Transparency International, 2018, p. 9. Reproduced under license CC BY-SA 4.0.

\section{Subnational level engagement}


Climate change finance information, particularly on adaption, is required at the local level but is commonly not available (UNDP \& IBP, 2018). The World Bank (2021, p. 9) note suggests using complementary reporting systems to extend the principles of climate budgeting beyond the central government as sub-national governments and state-owned enterprises are important climate policy actors. However, Allan et al. (2019, p. 25) emphasise that although efforts to expand climate tagging to the local level are relevant in fiscally decentralised contexts these can be demanding where local government PFM capacity and/or understanding of climate issues is limited.

The CABRI (2021b, p. 3) policy brief notes that "extending climate integration reforms to subnational governments has the potential to strengthen a country's fight against climate change with local contextualised response and budgeting, but this depends on the independence and autonomy of local governments." For example, in South Africa, the National Treasury has the flexibility to ensure provinces make enough budget provisions for climate change, including through establishing a provincial budget subprogramme on climate management under which the Treasury can track spending. Furthermore, provincial Medium Term Expenditure Framework guidelines emphasise the importance of budgets which are sensitive to climate issues, and regular budget visits by National Treasury to provinces, as well as a regular provincial benchmarking exercise which allows them to monitor progress, and through which they classify provinces into either advanced, emerging or beginner groupings based on the extent of their climate-informed budget processes.

\section{Expertise and capacity building support}

Gonguet et al. (2021) emphasise the need for specific expertise to be built up in order to successfully integrate climate change in ex-post evaluation and audit methodologies. This need for auditors to go beyond traditional auditing skills might explain why such practices have only been initiated in a few countries with extended green PFM experience such as Bangladesh. UNDP and IBP (2018, p. 24) highlight that civil society engagement in climate change finance accountability requires skills and knowledge on both climate change and public finance and budgeting. CSOs that have the capacity to play an effective role in public finance accountability are generally scarce. Limited capacity, poor sustainability, poor access to reliable financing, suspicion by government, and lack of incentives for coordination among CSOs are common problems for CSO climate change finance accountability work.

Another suggestion is the setting up of a dedicated independent body by a country to support the oversight of climate policies, such as a national climate change council, committee, or panel (for example, the Philippines' Committee on climate change). "The key to success for these institutions is to have a formal mandate and that it is seen both by the government and the public as an objective source of information, analysis, and advice to the government on the consistency of current policies with government targets and commitments" (Gonguet et al., 2021, p. 12).

Allan et al $(2019$, p. 6$)$ recommend that partners should support climate budgeting reforms in partner countries through sustained technical assistance, promulgation of tools and standards, and supporting existing peer learning forums (such as the Climate Action Peer Exchange and the 
soon-to-be-launched Asia and Pacific Climate Finance Network ${ }^{7}$ ). Strengthening oversight and engagement by accountability actors in the climate budgeting agenda include: CSOs and the media engaging more actively around how governments are allocating and managing public budgets for adaptation; legislatures routinely screening proposed budgets and government accounts for the same; and SAls developing climate-related standards for performance audit, and including climate change as an aspect when building up social audit practices. Donor agencies should finance capacity-building initiatives with the accountability actors, to facilitate the formation of coalitions and to open up avenues for dialogue with governments (Allan et al., 2019, p. 6).

UNDP and IBP (2018, p. 24) recommend that international actors interested in improving climate change finance accountability, and building the capacity of CSOs to engage, should consider the incentives for CSO behaviour and their financial needs for sustained engagement. Climate change accountability can be incorporated into development accountability work of existing organisations with existing skills - this is an entry point to consider (UNDP \& IBP, 2018, p. 25). International actors can also support institutions that build media capacity (either generally, or specifically in climate change or budget work) to develop their own capacity in climate change financing work.

\section{Continuous political-economy analysis and contextual assessment}

The country's political-economy and context will heavily influence the effectiveness and success of social accountability processes and actors. Hence, CSOs and other nongovernmental actors involved in holding decision-makers accountable should continually assess the political economy context for improving climate finance accountability, including participation in decision-making, and assessing vested interests (Krishnan, 2020, p. 3). The political-economy and context of a country will also be key to understanding the extent to which these non-governmental actors are able to voice their opinions on government policies. If open civic space for engagement is limited, then social accountability interventions will also likely be limited in their success. Assessing the changing civic space will be critical to understanding whether CSO-led efforts to ensure the accountability of climate finance flows will be successful. There have been concerted efforts to build CSO's capacities to play these social accountability roles, through focusing, for example, on bolstering their ability to analyse, research, build networks and advocate on certain issues (Krishnan, 2020, p. 6). However, these programmes in relation to tracking climate finance flows and facilitate community-government discussions on adaptation-related issues are in their infancy (Krishnan, 2020, p. 14). Further practice and research is needed (see Worker \& Palmer, 2021 for further guidance on assessing the political-economy of domestic climate change governance. See also Price, 2021b and Lucas, 2019).

\footnotetext{
7 See https://climatefinancenetwork.org/
} 


\section{References}

Allan, S., Bahadur, A.V., Venkatramani, S. \& Soundarajan, V. (2019). The role of domestic budgets in financing climate change adaptation: A background paper for the global Commission on adaptation. Oxford Policy Management. https://gca.org/wpcontent/uploads/2020/12/The_Role_of_Domestic_Budgets_in_Financing_Paper_Final.pd $f$

Bird, N. \& Granoff, I. (2016). National monitoring approaches for climate change public finance. Mexico DF: Deutsche Gesellschaft für Internationale Zusammenarbeit (GIZ) GmbH. https://cdn.odi.org/media/documents/10663.pdf

CABRI. (2021a). The integration of climate change into budgeting and finance: Keynote Paper. Inclusive Budgeting and Financing for Climate Change in Africa programme (IBFCCA). Pretoria: CABRI, Swedish International Development Cooperation Agency (SIDA), the United Nations Development Programme (UNDP), the International Institute for Environment and Development (IIED) \& the International Budget Partnership (IBP). https://www.cabri-sbo.org/en/publications/inclusive-budgeting-and-financing-for-climatechange-in-africa

CABRI. (2021b). The integration of climate change into budgeting and finance: Policy Brief. Inclusive Budgeting and Financing for Climate Change in Africa programme (IBFCCA). Pretoria: CABRI, Swedish International Development Cooperation Agency (SIDA), the United Nations Development Programme (UNDP), the International Institute for Environment and Development (IIED) \& the International Budget Partnership (IBP). https://www.cabri-sbo.org/uploads/files/Documents/CABRI-Policy-Brief-Climate-changefinancining-English.pdf

CABRI. (2021c). Climate finance accountability in Africa: Keynote Paper. Inclusive Budgeting and Financing for Climate Change in Africa programme (IBFCCA). Pretoria: CABRI, SIDA, UNDP, IIED \& IBP. https://www.cabri-sbo.org/uploads/files/Documents/Keynote-paperClimate-finance-accountability-in-Africa_210910_171921.pdf

Di Gregorio, M., Fatorelli, L., Paavola, J., Locatelli, B., Pramova, E., Nurrochmat, D. R., May, P.H., Brockhaus, M., Sari, I.M. \& Kusumadewi, S. D. (2019). Multi-level governance and power in climate change policy networks. Global Environmental Change, 54, 64-77. https://doi.org/10.1016/j.gloenvcha.2018.10.003

Gogoi, E., Bahadur, A.V. \& Rumbaitis del Rio, C. (2017). Mainstreaming adaptation to climate change within governance systems in South Asia: An analytical framework and examples from practice. ACT Learning Paper. Oxford: OPM.

https://www.opml.co.uk/files/Publications/8617-action-on-climate-today-act/mainstreamingadaptation-to-climate-change-within-governance-systems-in-south-asia.pdf?noredirect=1

Gonguet, F., Wendling, C., Aydin, O. \& Battersby, B. (2021). Climate-Sensitive Management of Public Finances - "Green PFM." IMF Staff Climate Note 2021/002. Washington, D.C.: International Monetary Fund. https://www.imf.org/en/Publications/staff-climatenotes/Issues/2021/08/10/Climate-Sensitive-Management-of-Public-Finances-Green-PFM460635

Higham, C., Averchenkova, A., Setzer, J. \& Koehl, A. (2021). Accountability Mechanisms in Climate Change Framework Laws. London: Grantham Research Institute, LSE. https://www.Ise.ac.uk/granthaminstitute/wp-content/uploads/2021/11/Accountabilitymechanisms-in-climate-change-framework-laws.pdf 
Krishnan, N. (2020). “Following the Money Isn't Enough.” Working Paper. Washington, DC: World Resources Institute. www.wri.org/publication/followingthe-money

Laws, E., \& Marquette, H. (2018). Thinking and working politically: reviewing the evidence on the integration of politics into development practice over the past decade. Birmingham, UK: University of Birmingham. https://twpcommunity.org/wp-content/uploads/2018/04/Thinkingand-working-politically-reviewing-the-evidence.pdf

Lucas, B. (2019). Political will of African governments to address climate change. K4D Helpdesk Report 701. Brighton, UK: Institute of Development Studies. https://opendocs.ids.ac.uk/opendocs/handle/20.500.12413/14813

Patel, S., Soanes, M., Rahman, F., Smith, B. \& Steinbach, D. (2020). Good climate finance guide: lessons for strengthening devolved climate finance. IIED Working Paper, IIED, London. http://pubs.iied.org/10207IIED

Price, R.A. (2019). Mainstreaming climate and environmental considerations into existing development programmes. K4D Helpdesk Report 541. Brighton, UK: Institute of Development Studies. https://opendocs.ids.ac.uk/opendocs/handle/20.500.12413/14375

Price, R.A. (2021a). Access to climate finance by women and marginalised groups in the Global South. K4D Helpdesk Report 1004. Institute of Development Studies. DOI: 10.19088/K4D.2021.083

Price, R.A. (2021b). Overview of political economy analysis frameworks in the area of climate governance and key issues to consider. K4D Helpdesk Report1014. Institute of Development Studies. DOI: 10.19088/K4D.2021.088

Resch, E., Allan, S., Álvarez, L.G. \& Bisht, H. (2017). Mainstreaming, accessing and institutionalising finance for climate change adaptation. ACT Learning Paper. Oxford: OPM. Link

Runhaar, H., Wilk, B., Persson, Å., Uittenbroek, C., \& Wamsler, C. (2018). Mainstreaming climate adaptation: taking stock about "what works" from empirical research worldwide. Regional environmental change, 18(4), 1201-1210. https://doi.org/10.1007/s10113-0171259-5

Schmitz, H. (2016). Who drives climate-relevant policies in rising powers? IDS Evidence Report 180. Brighton: Institute of Development Studies.

https://opendocs.ids.ac.uk/opendocs/handle/20.500.12413/9933

Tanner, T., Zaman, R.U. \& Acharya, S. (2018). Influencing adaptation policy: The role of policy entrepreneurs in securing ownership and climate action in South Asia. ACT Learning Paper. Oxford: OPM.

http://www.indiaenvironmentportal.org.in/files/file/Influencing\%20adaptation\%20policy.pdf

Transparency International. (2018). Climate Adaptation Finance Governance Standards: a New Approach Piloted in the Maldives and Bangladesh. Berlin: Transparency International. https://www.transparency.org/en/publications/climate-adaptation-finance-governancestandards

UNDP. (2021). Budgeting for Climate Change: A Guidance Note for Governments to Integrate Climate Change into Budgeting. Technical Note Series. https://www.undp.org/publications/ budgeting-climate-change-guidance-note-governments-integrate-climate-change-

budgeting 
UNDP \& IBP. (2018). Budgeting for a greener planet: An assessment of climate change finance accountability in Bangladesh, India, Nepal, and the Philippines - Summary report. Link

UNICEF. (2020). What is climate governance? Panamá: UNICEF. https://www.unicef.org/lac/media/19651/file/what-is-climate-governance.pdf

Van Zyl, A. (2014). How Civil Society Organizations close the gap between Transparency and Accountability. Governance, 27(2), 347-356. https://doi.org/10.1111/gove.12073

Whaites, A. (2017). The Beginner's Guide to Political Economy Analysis (PEA). National School of Government International (NSGI), UK AID.

https://assets.publishing.service.gov.uk/government/uploads/system/uploads/attachment _data/file/766478/The_Beginner_s_Guide_to_PEA.pdf

Worker, J. (2017). National climate change governance: Topic guide. Birmingham, UK: GSDRC, University of Birmingham. https://gsdrc.org/wp-content/uploads/2016/08/NatCCGov.pdf

Worker, J., \& Palmer, N. (2021). "A Guide to Assessing the Political Economy of Domestic Climate Change Governance." Working Paper. Washington, DC: World Resources Institute. doi.org/10.46830/wriwp.18.00047

World Bank. (2014). Moving Toward Climate Budgeting: Policy Note. Washington, DC: World Bank. https://openknowledge.worldbank.org/handle/10986/21036

World Bank. (2021). Climate Change Budget Tagging: A Review of International Experience. Equitable Growth, Finance and Institutions Insight. Washington, DC: World Bank. https://openknowledge.worldbank.org/handle/10986/35174

\section{Suggested citation}

Price, R.A. (2021). Climate adaptation: lessons and insights for governance, budgeting, and accountability. K4D Helpdesk Report 1073. Institute of Development Studies. DOI: 10.19088/K4D.2022.008

\section{About this report}

This report is based on twelve days of desk-based research. The K4D research helpdesk provides rapid syntheses of a selection of recent relevant literature and international expert thinking in response to specific questions relating to international development. For any enquiries, contact helpdesk@k4d.info.

K4D services are provided by a consortium of leading organisations working in international development, led by the Institute of Development Studies (IDS), with the Education Development Trust, Itad, University of Leeds Nuffield Centre for International Health and Development, Liverpool School of Tropical Medicine (LSTM), University of Birmingham International Development Department (IDD) and the University of Manchester Humanitarian and Conflict Response Institute (HCRI).

This report was prepared for the UK Government's Foreign, Commonwealth \& Development Office (FCDO) and its partners in support of pro-poor programmes. Except where otherwise stated, it is licensed for non-commercial purposes under the terms of the Open Government Licence v3.0. K4D cannot be held responsible for errors or any consequences arising from the use of information contained in this report. Any views and opinions expressed do not necessarily reflect those of $\mathrm{FCDO}, \mathrm{K} 4 \mathrm{D}$ or any other contributing organisation.

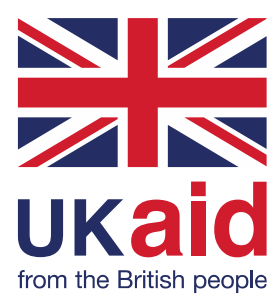

(C) Crown copyright 2021 